Free-standing $\mathrm{ZnO}-\mathrm{CuO}$ composite nanowire array films and their gas sensing properties

This article has been downloaded from IOPscience. Please scroll down to see the full text article.

2011 Nanotechnology 22325704

(http://iopscience.iop.org/0957-4484/22/32/325704)

View the table of contents for this issue, or go to the journal homepage for more

Download details:

IP Address: 139.179.14.46

The article was downloaded on 26/11/2012 at $11: 29$

Please note that terms and conditions apply. 


\title{
Free-standing $\mathrm{ZnO}-\mathrm{CuO}$ composite nanowire array films and their gas sensing properties
}

\author{
J X Wang ${ }^{1}$ X W Sun ${ }^{1,2}$, Y Yang ${ }^{1}$, K K A Kyaw ${ }^{1}$, X Y Huang ${ }^{1}$, \\ J Z Yin ${ }^{1}$, J Wei ${ }^{3}$ and $H$ V Demir ${ }^{1,4}$ \\ ${ }^{1}$ School of Electrical and Electronic Engineering, Nanyang Technological University, \\ Nanyang Avenue, 639798, Singapore \\ ${ }^{2}$ Department of Applied Physics, College of Science, Tianjin University, Tianjin 300072, \\ People's Republic of China \\ ${ }^{3}$ Singapore Institute of Manufacturing Technology (SIMTech), 71 Nanyang Drive, 638075, \\ Singapore \\ ${ }^{4}$ Department of Electrical and Electronics Engineering, Department of Physics, \\ UNAM-Institute of Material Science and Nanotechnology, Bilkent University, Ankara 06800, \\ Turkey \\ E-mail: exwsun@ntu.edu.sg
}

Received 15 March 2011, in final form 23 June 2011

Published 19 July 2011

Online at stacks.iop.org/Nano/22/325704

\begin{abstract}
A modified hydrothermal method was developed to synthesize $\mathrm{ZnO}-\mathrm{CuO}$ composite nanostructures. A free-standing film made of $\mathrm{ZnO}-\mathrm{CuO}$ nanostructures was assembled on the surface of the hydrothermal solution with a smooth surface on one side and a spherical surface on the other side. The structure, growth mechanism and the optical properties of the composite nanostructures were studied. Structural characterizations indicate that the composite nanostructure mainly consisted of two single-crystal phases of $\mathrm{CuO}$ and $\mathrm{ZnO}$. The sensitivity for $\mathrm{CO}$ gas detection was significantly improved for the composite $\mathrm{CuO}-\mathrm{ZnO}$ nanostructure film. This method offers a possible route for the fabrication of free-standing nanostructure films of different functional composite oxides.
\end{abstract}

S. Online supplementary data available from stacks.iop.org/Nano/22/325704/mmedia

(Some figures in this article are in colour only in the electronic version)

\section{Introduction}

One-dimensional (1D) metal oxide nanostructures with various morphologies, such as nanowires [1], nanotubes [2] and nanoflower [3], have been extensively investigated during the past few years. Among them, composite nanomaterials consisting of different components along the axial or radial directions may offer a combined functionality contributed by these different components. Various methods, including thermal evaporation $[4,5]$, chemical vapor deposition [6] and wet chemical method [7], have been developed to fabricate various types of composite nanowires such as $\mathrm{ZnO} / \mathrm{ZnS}$, $\mathrm{CdS} / \mathrm{ZnS}, \mathrm{Zn} / \mathrm{ZnO}$ and $\mathrm{In}_{2} \mathrm{O}_{3} / \mathrm{SnO}_{2}$. However, up to now, effective strategies for reliable and mass fabrication of composite nanostructures still remain a challenge. In addition, most of the nanostructures need to be synthesized on the substrate because it provides a platform for deposition of the catalysts or the seed layer, which is important for the growth of nanostructures. However, the usage of substrates sometimes limits their wide applications in electronic devices, especially when the substrate is non-conductive. Complicated procedures need to be carried out to form the electrical contact, for example, separating the film and transferring to other substrates [8]. Direct fabrication of the free-standing film is a viable solution to overcome these limitations.

$\mathrm{ZnO}$ is a traditional n-type semiconductor due to the existence of oxygen vacancies. $\mathrm{ZnO}$ nanostructures have attracted intense research interest due to their aesthetic morphologies and potential optical and electrical applications, such as field emitter [9], ultraviolet laser [1], biosensor [10], 
gas sensor [11, 12] and transistor [13]. On the other hand, $\mathrm{CuO}$ is a p-type transition-metal oxide with a narrow bandgap $\left(E_{\mathrm{g}} \sim 1.2 \mathrm{eV}\right)$. Their nanostructures have been extensively studied in recent years and have been considered as a promising materials in many fields such as gas sensors [14], lithium ion electrode materials [15] and field emission emitters [16]. Composite nanostructures of $\mathrm{ZnO}$ and $\mathrm{CuO}$ may form a $\mathrm{p}-\mathrm{n}$ junction in a one-dimensional scale. It is expected that the nanocomposites of $1 \mathrm{D} \mathrm{ZnO}$ and $\mathrm{CuO}$ nanomaterials exhibit novel or improved properties in different fields such as gas sensors and field emitters.

In this paper, we shall report a modified hydrothermal method for the synthesis of a composite coaxial $\mathrm{ZnO}$ $\mathrm{CuO}$ nanostructure, which forms a free-standing film on the surface of the hydrothermal solution. The structures, growth mechanism and optical properties as well as their gas sensing properties of the composite nanostructures were studied.

\section{Experimental details}

The $\mathrm{ZnO}-\mathrm{CuO}$ composite nanowires were fabricated by a modified hydrothermal method. The reaction solution was prepared by mixing $0.05 \mathrm{~mol}^{-1} \mathrm{ZnCl}_{2}, 0.001 \mathrm{mM} \mathrm{CuCl}_{2}$ and a proper quantity of ammonia (weight ratio $25 \%$ ) in a bottle with an autoclavable screw. The $\mathrm{pH}$ value of the solution was adjusted by ammonia and kept at 10 . Unlike the traditional hydrothermal method using a closed vessel as the reactor, in our experiment a small hole with a diameter of about $1.5 \mathrm{~mm}$ was opened on the top of the autoclavable screw cap. The solution was slowly heated up to $95^{\circ} \mathrm{C}$ with a rate of about $1-2{ }^{\circ} \mathrm{C} \min ^{-1}$, then the temperature was kept constant for 8 h. Finally, a free-standing black film was found floating on the surface of the solution. The area of the film can reach several square centimeters. Subsequently, the as-prepared film was washed repeatedly with the deionized water and dried at $90^{\circ} \mathrm{C}$ for $1 \mathrm{~h}$. Then the structure and the morphologies of the film were characterized using scanning electron microscopy (SEM, JEOL JSM-5910), x-ray diffraction (XRD, Siemens D5005) and high-resolution transmission electron microscopy (HRTEM, JEOL TEM-2010F). The optical properties of the composite film were investigated using room temperature (RT) Raman spectroscopy and RT photoluminescence (PL). The gas sensing properties of the $\mathrm{ZnO}-\mathrm{CuO}$ composite were characterized using a computer-controlled gas-sensing characterization system. The testing gas was diluted $\mathrm{CO}$ in dry air with a total flow rate of $500 \mathrm{sccm}$. The gas sensitivity $S$ was determined by the relative resistance, $S=R_{\text {air }} / R_{\text {gas }}$, where $R_{\text {air }}$ and $R_{\text {gas }}$ are the resistance of the $\mathrm{ZnO}-\mathrm{CuO}$ composite gas sensor in dry air and in dry air with $\mathrm{CO}$ gas, respectively.

\section{Results and discussion}

Typical SEM images of the composite film are shown in figure 1. Figure 1(a) shows a top-view SEM image taken on the central region of the composite $\mathrm{ZnO}-\mathrm{CuO}$ film. The image indicates that the composite film is assembled by many grainlike structures made of dense nanowires. The size of the grainlike structure can reach up to several tens of micrometers. Clear interfaces between the hierarchical structures are observed, as indicated by the arrows in figure 1(a). Interestingly, for each hierarchical structure, we observed that most of the nanowires grew horizontally but towards different orientations, forming a nanostructure film with a flat surface. Figure 1(b) presents the SEM image taken on the edge of the nanostructured film. Without the confinement of other grains, the edge of the nanowire film grows in an arc-like shape. A high magnification SEM image shown in the inset of figure 1(b) shows that the nanowires assembled at the edge of the film have a diameter of about $100 \mathrm{~nm}$ and the lengths ranged from several hundred nanometers to several micrometers. Due to the free-standing feature of the nanowire film, it is easy to be manipulated by tweezers and thus we can investigate the morphology of the nanowire film on the other side. Figures 1(c) and (d) presents the top-view SEM image of the nanowire film on the other side. Although from the images, we can also find many boundaries in between the grains, the morphology of the film is quite different. Unlike the flat surface shown in figure 1(a), the surface of the grains on this side is developed to a spherical shape. The surface of the composite film looks like the assembling of many partial spherical crowns, which makes the surface of the film quite rough. The nanowires grew on the surface have the diameter of about $100 \mathrm{~nm}$, which is the same as the nanowires grown on the flat side. The cross-sectional SEM images shown in figures $1(\mathrm{e})$ and (f) give us a clear view of the composite nanowire film. As can be seen from the images, we can observe that the film consists of many spherical hierarchical structures, and the nanowires grow radially and perpendicularly to the spherical face.

The XRD pattern of the nanowire film is shown in figure 2, where most of the diffraction peaks can be indexed to the hexagonal wurtzite phase of $\mathrm{ZnO}$ with lattice constants of $a=0.325 \mathrm{~nm}$ and $c=0.520 \mathrm{~nm}$ (JCPDS 80-0074). The left diffraction peaks, as indicated in the figure, are indexed to those of the monoclinic phase of CuO (JCPDS 80-1916). No other composite phase was found, which indicates the nanowire film is consisted of two different phases of $\mathrm{ZnO}$ and $\mathrm{CuO}$.

Figure 3(a) shows the bright-field TEM image of a nanowire with a diameter of about $50 \mathrm{~nm}$. From the TEM image, we can observe that the nanowire shows a thin tip with different contrast (marked by squares). The corresponding SAED taken from the tip is shown in the bottom-left inset of figure 3(a). Regular and bright spots of the SAED indicate the single-crystalline feature of the nanowire. The SAED is indexed to be monoclinic phase $\mathrm{CuO}$ taken along the [101] zone axis. The growth direction of the nanowire can also be determined to be the [020] direction of $\mathrm{CuO}$. However, the SAED taken from the center of the nanowire shows a different pattern (circle region), as shown in the top-right inset of figure 3(a). The SAED pattern indicates two sets of diffraction spots. One can be indexed to be a hexagonal $\mathrm{ZnO}$ pattern along the [0111] zone axis. Another set of SAED patterns belongs to monoclinic $\mathrm{CuO}$ along the [101] zone axis, which is the same as the SAED pattern taken from the tip of the nanowire. The SAED results clearly demonstrate that the nanowire consisted of two different phases of $\mathrm{ZnO}$ and $\mathrm{CuO}$. Figure 3(b) shows an 


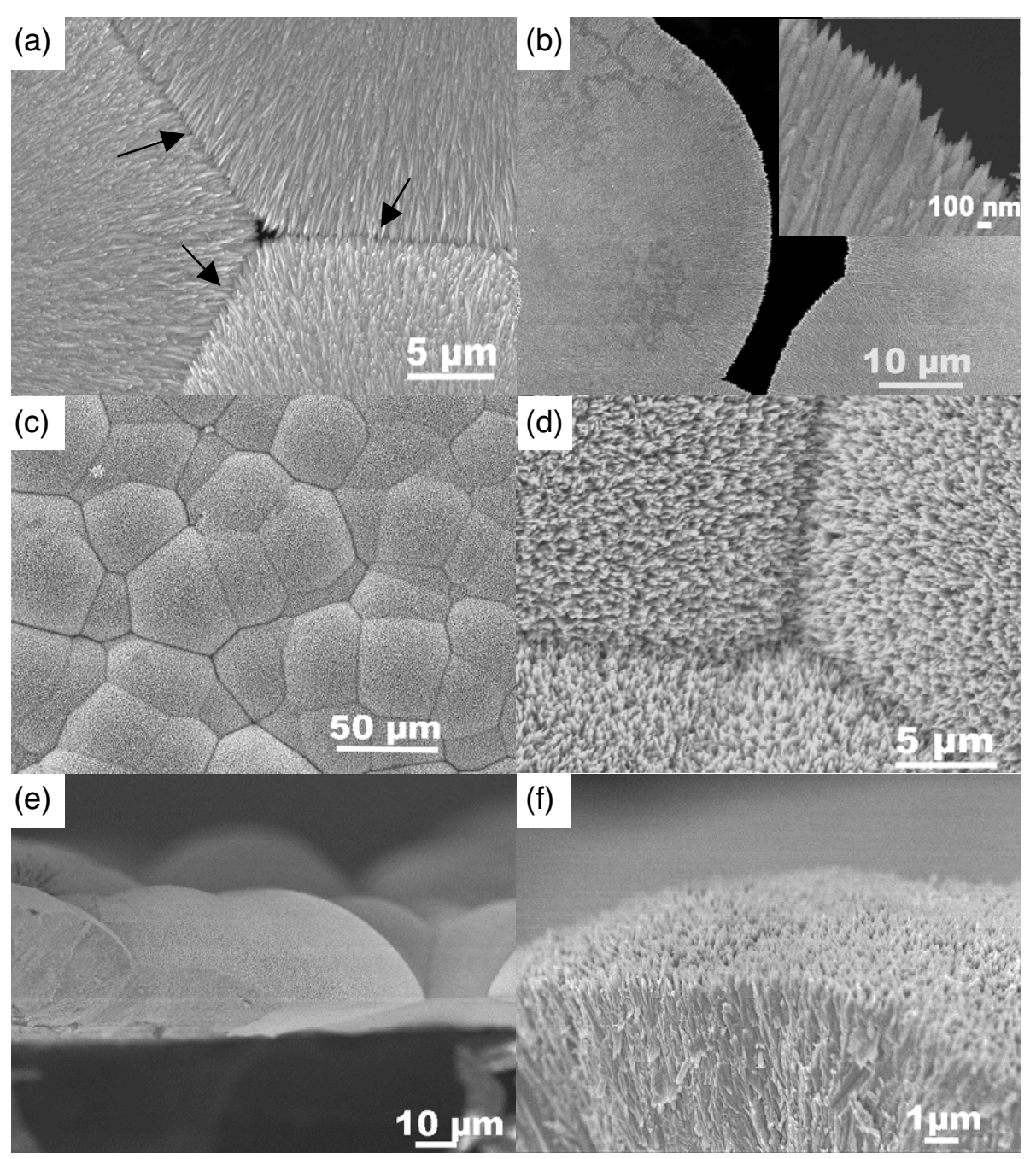

Figure 1. Top-view SEM images of (a) composite $\mathrm{ZnO}-\mathrm{CuO}$ film taken on the central region and (b) edge of the composite film. Inset is the enlarged SEM image taken on the edge of the composite film (c). (d) Top-view SEM image of the composite film on another side. (e) Cross-sectional SEM image of composite film. (f) Enlarged cross-sectional SEM image of composite film.

HRTEM image taken from the edge of the nanowire. A clear interface between two phases can be observed with different contrasts. At the region above the interface, two groups of parallel fringes with a $d$ spacing of 0.25 and $0.23 \mathrm{~nm}$ can be indexed, which correspond to the $(\overline{1} 1 \overline{1})$ and (111) planes of monoclinic $\mathrm{CuO}$, respectively. In addition, at the edge of the nanowires, another two groups of the parallel fringes can be indexed to the (1101) and (1011) planes of wurtzite $\mathrm{ZnO}$, respectively. The TEM and HRTEM results demonstrated that the nanowire is a composite structure with two separate phases $\mathrm{CuO}$ and $\mathrm{ZnO}$, respectively.

It is worth mentioning that no composite nanostructures were found on the silicon substrate placed on the bottom of the solution. Instead, $\mathrm{ZnO}$ nanorod arrays with uniform diameters and lengths were observed (see supporting information, figure S1 available at stacks.iop.org/Nano/22/325704/mmedia). TEM analysis indicated that all the growth direction of the $\mathrm{ZnO}$ nanorods is in the [0001] direction (see supporting information, figure S1 available at stacks.iop.org/Nano/22/ $325704 /$ mmedia), which is different from the direction of the $\mathrm{ZnO}$ shell coated on the $\mathrm{CuO}$ surface. Obviously, the growth

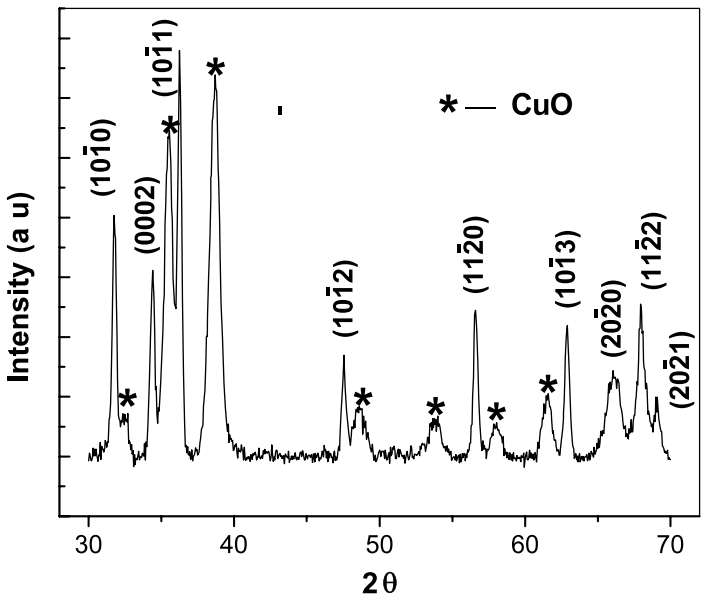

Figure 2. XRD pattern of the composite $\mathrm{ZnO}-\mathrm{CuO}$ nanostructure film.

orientation of the $\mathrm{ZnO}$ was confined by the $\mathrm{CuO}$ phase. As we know, composite structures can form easily when the planes of the two different materials have close inter-plane 


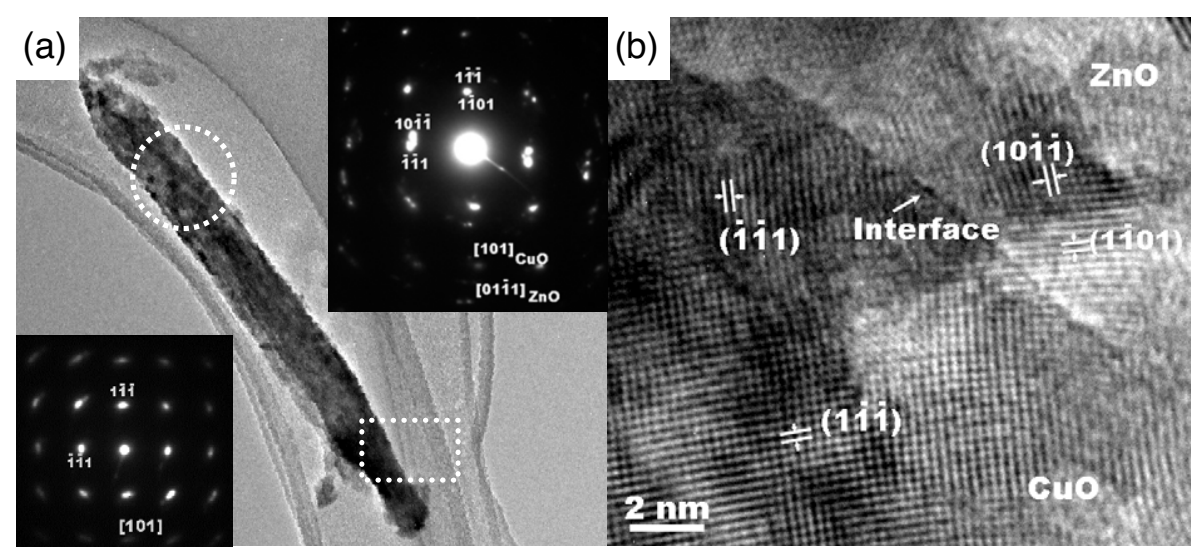

Figure 3. (a) Bright-field TEM image of a nanowire. The insets are SAED patterns taken from the tip (bottom left) and the center (top right) of the nanowire. (b) HRTEM image of the composite $\mathrm{ZnO}-\mathrm{CuO}$ nanowires.

spacing and similar crystal orientations as well as similar crystal structures. The similar phenomenon was also observed in the $\mathrm{ZnO}-\mathrm{SnO}_{2}$ composite system [17]. In this work, $\mathrm{CuO}$ has a monoclinic structure while $\mathrm{ZnO}$ has a hexagonal wurtzite structure. However, the $\mathrm{CuO}\{111\}$ and $\mathrm{ZnO}\{\overline{1} 011\}$ planes have an inter-plane spacing of $0.252 \mathrm{~nm}$ and $0.247 \mathrm{~nm}$, respectively. The angle between the $\mathrm{CuO}(111)$ and $(\overline{1} 1 \overline{1})$ planes is $84^{\circ}$, which is close to the included angle between the $\mathrm{ZnO}$ (1011) and $(10 \overline{1} \overline{1})$ (calculated to be $80^{\circ}$ ). The mismatch between these crystal planes are relatively small and thus of benefit to form the composite $\mathrm{CuO}-\mathrm{ZnO}$ structure.

Figure 4(a) shows the room temperature Raman spectrum of the $\mathrm{ZnO}-\mathrm{CuO}$ core shell structures. As a reference, the Raman spectrum of pure $\mathrm{ZnO}$ nanowire arrays grown at the same condition is also presented. As we know, wurtzite $\mathrm{ZnO}$ belongs to the space group of $C 6 v$, with six active Raman modes of $E_{2 L}+E_{2 H}+A_{1 T}+A_{1 L}+E_{1 T}+E_{1 L}[18,19]$. The Raman spectrum of the pure $\mathrm{ZnO}$ nanowire arrays exhibited six peaks at 202, 330, 380, 436, 574 and $658 \mathrm{~cm}^{-1}$. Among these peaks, the three peaks at 380,436 and $576 \mathrm{~cm}^{-1}$ are assigned to $A_{1 T}, E_{2 H}$ and $A_{1 L}$ modes, respectively, while the peaks at 202, 380 and $658 \mathrm{~cm}^{-1}$ emerged due to the multiphonon processes. The three peaks were assigned to $2 \mathrm{E}_{2 \mathrm{~L}}$, $\left[E_{2 L}-E_{2 H}\right]$ and $\left[E_{2 L}+B_{1 H}\right]$ modes, respectively. Compared to pure $\mathrm{ZnO}$ nanowires, the Raman spectrum of the $\mathrm{ZnO}-$ $\mathrm{CuO}$ composite structure shows two additional peaks at 286 and $627 \mathrm{~cm}^{-1}$. These two peaks correspond to the $A_{1 \mathrm{~g}}$ and $\mathrm{B}_{2 \mathrm{~g}}$ modes of crystalline $\mathrm{CuO}$ due to the vibrations of the oxygen atoms. However, compared to the literature [20], a redshift of the Raman peaks is observed. This may be due to the introduction of the stress during the growth process of the composite nanostructures. The coexistence of the $\mathrm{CuO}$ and $\mathrm{ZnO}$ Raman modes in the Raman spectra further confirms that the structure is a composite nanostructure, consistent with the XRD and TEM results.

Figure 4(b) shows the room temperature PL spectrum of the $\mathrm{ZnO}-\mathrm{CuO}$ composite nanowires as well as the pure $\mathrm{ZnO}$ nanowires excited by a $325 \mathrm{~nm} \mathrm{He}-\mathrm{Cd}$ laser. As we can see from the spectra, the PL of the pure $\mathrm{ZnO}$ nanowires shows a sharp peak centered at $382 \mathrm{~nm}$ and a very weak broad band ranging from the green to the red region. The
UV peak at $382 \mathrm{~nm}$ is ascribed to the near-band-edge exciton recombination [21]. Compared to the $\mathrm{PL}$ of the $\mathrm{ZnO}$ nanowire, the $\mathrm{PL}$ of the as-prepared $\mathrm{ZnO}-\mathrm{CuO}$ composite nanowires only shows a broad band with three shoulder peaks at 600, 627 and $665 \mathrm{~nm}$, respectively. This broad band is attributed to the luminescence of the native or dopant-induced defects in $\mathrm{ZnO}-\mathrm{CuO}$ nanowires [22]. It is worth noticing that the three shoulder peaks at 600, 628 and $665 \mathrm{~nm}$ can be ascribed to the $\mathrm{PL}$ of the $\mathrm{ZnO}$ phase, which have been observed in $\mathrm{ZnO}$ nanowires and films [23-25]. The peaks at 600 and $628 \mathrm{~nm}$ may be caused by the monovalent vacancies of zinc $\left(\mathrm{V}_{\mathrm{Zn}}^{+}\right)$and $\left(\mathrm{Vo}^{-}\right)$, while the red peak at $665 \mathrm{~nm}$ is attributed to the singleand double-ionized oxygen vacancies. No PL-peak-related $\mathrm{CuO}$ phase were observed. Therefore, the PL is originated from the luminescence of the $\mathrm{ZnO}$ grown on the surface of the $\mathrm{CuO}$ nanowires. Usually, $\mathrm{Cu}$ doping in $\mathrm{ZnO}$ usually leads to the green emission [26, 27]. However, in our case, the green emission was not obvious, which may indicate $\mathrm{Cu}$ doping may not be significant in our $\mathrm{ZnO}-\mathrm{CuO}$ composite nanostructure. The PL of the $\mathrm{ZnO}-\mathrm{CuO}$ composite nanowires annealed in oxygen at $500{ }^{\circ} \mathrm{C}$ for 3 and $8 \mathrm{~h}$ are also shown in figure $4(\mathrm{~b})$. After annealing, the UV peak at $382 \mathrm{~nm}$ was observed and the intensity of the peaks increases while the intensity of the broad band reduces with the increase in annealing time. This may be due to the reduction of the crystal defects in the $\mathrm{ZnO}$ layer during the annealing process.

According to the above experimental observation, we investigated the growth mechanism of the $\mathrm{ZnO}-\mathrm{CuO}$ composite nanowire film. As we know, metal ions such as $\mathrm{Cu}^{2+}$ and $\mathrm{Zn}^{2+}$ can react with the excess $\mathrm{NH}_{3} \cdot \mathrm{H}_{2} \mathrm{O}$ to form amino complexes easily. When the amino complexes were heated, they decomposed to $\mathrm{CuO}$ and $\mathrm{ZnO}$, respectively. The following reactions should take place in the aqueous solutions:

$$
\begin{gathered}
\mathrm{Cu}^{2+}+\mathrm{NH}_{3} \cdot \mathrm{H}_{2} \mathrm{O} \leftarrow \mathrm{Cu}\left(\mathrm{NH}_{3}\right)_{4}^{2+} \\
+\mathrm{OH}^{-} \leftarrow \rightarrow \mathrm{CuO}+\mathrm{NH}_{3}+\mathrm{H}_{2} \mathrm{O} \\
\mathrm{Zn}^{2+}+\mathrm{NH}_{3} \cdot \mathrm{H}_{2} \mathrm{O} \leftarrow \rightarrow \mathrm{Zn}\left(\mathrm{NH}_{3}\right)_{4}^{2+} \\
+\mathrm{OH}^{-} \leftarrow \rightarrow \mathrm{ZnO}+\mathrm{NH}_{3}+\mathrm{H}_{2} \mathrm{O} .
\end{gathered}
$$

For the formation of composite $\mathrm{ZnO}-\mathrm{CuO}$ nanostructures, $\mathrm{CuO}$ nanowires will form first at an early stage before the 

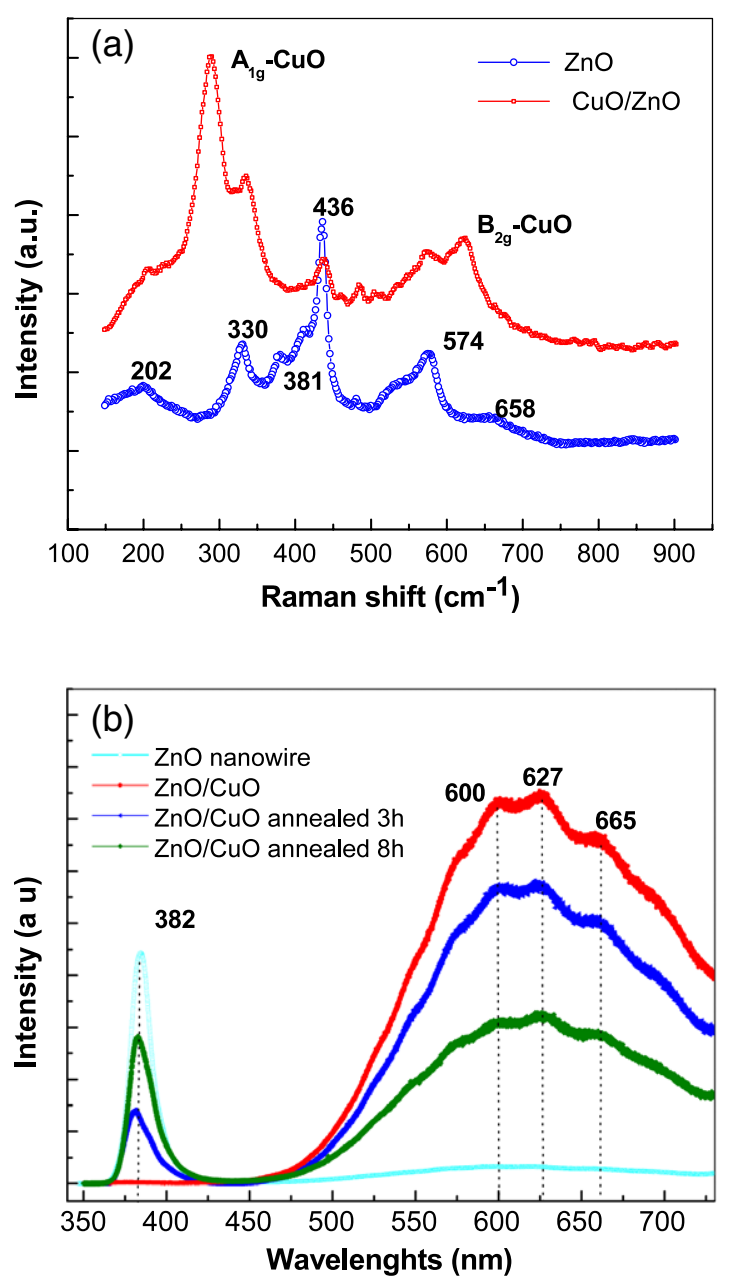

Figure 4. (a) Raman spectrum of composite $\mathrm{ZnO}-\mathrm{CuO}$ nanostructure film and pure $\mathrm{ZnO}$ nanowire array. (b) Room temperature $\mathrm{PL}$ spectrum of the $\mathrm{ZnO}-\mathrm{CuO}$ composite nanowires and pure $\mathrm{ZnO}$ nanowire array.

precipitation of the $\mathrm{ZnO}$ phase. This assumption is supported by our experiment results; we found that the $\mathrm{CuO}$ can be easily precipitated from solution below $75^{\circ} \mathrm{C}$. However, at this temperature, $\mathrm{ZnO}$ cannot be formed. Therefore, when the solution was slowly heated up to $95^{\circ} \mathrm{C}$, the $\mathrm{CuO}$ phase will first be precipitated. Due to the small concentration of $\mathrm{Cu}^{2+}$ in the reactant, the $\mathrm{Cu}^{2+}$ in solution vanished after the precipitation of the $\mathrm{CuO}$. When the temperature keeps rising and reaches the critical value for $\mathrm{ZnO}$ precipitation, $\mathrm{ZnO}$ will precipitate on the surface of the $\mathrm{CuO}$ nanowires forming composite $\mathrm{ZnO}-\mathrm{CuO}$ structures.

We found the small hole on the screw cap played an important role in the formation of the free-standing films. In our experiment, no films can be formed on the solution without the hole in the screw. Owing to the existence of the small hole, $\mathrm{NH}_{3}$ and water can escape slowly from the hole when the solution is heated up. The reduction of $\mathrm{NH}_{3}$ and $\mathrm{H}_{2} \mathrm{O}$ will move the reactions (1) and (2) to the right and thus facilitate the precipitation of the oxides. Most importantly, the evaporation of the $\mathrm{NH}_{3}$ and $\mathrm{H}_{2} \mathrm{O}$ will first occur in a thin layer on the solution-air interface. Therefore, in this region, $\mathrm{NH}_{3}$ and $\mathrm{H}_{2} \mathrm{O}$ will escape first: as a result, reactions

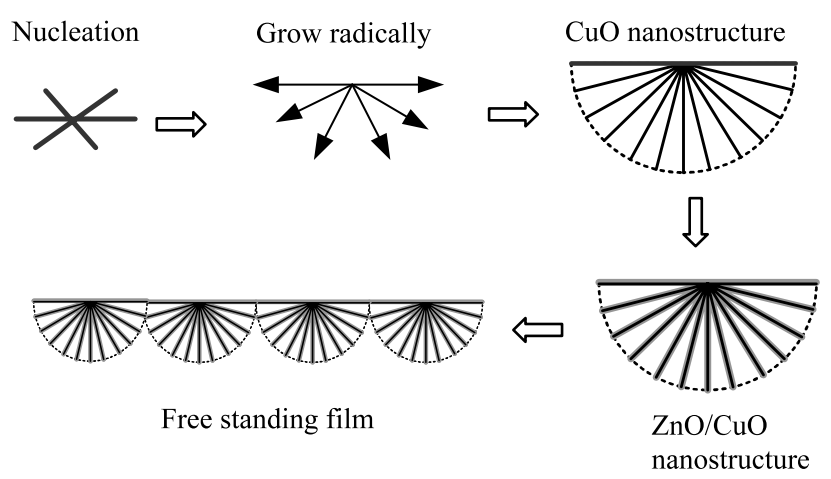

Figure 5. Schematic illustrations of the growth process of the composite $\mathrm{ZnO}-\mathrm{CuO}$ nanostructure film.

take place first at the surface of the solution, which was supported by the fact that the free-standing film formed only on the surface of the solution. A schematic model shown in figure 5 is used to illustrate the synthesis process of the freestanding film. First, the composite nanostructures nucleated on the surface of the solution and then grew radially towards the solution because the reactants can only come from the solution. Subsequently, the composite nanostructure developed into hierarchical spherical structures floating on the surface of the solution due to the surface tension. With further growth of the hierarchical structures, the hierarchical structures connect to each other, forming a free-standing film. Because of the confinement of the solution surface, the nanowires can only grow horizontally at the surface plane and thus finally form a flat surface on one side of the composite film.

$\mathrm{ZnO}$ is a traditional sensing material for the detection of toxic and flammable gases. However, compared to other gases such as $\mathrm{H}_{2}$ and $\mathrm{NH}_{3}, \mathrm{ZnO}$ is less sensitive for the detection of $\mathrm{CO}$ gas because the detection of gases is mainly based on the catalytic oxidation of gas molecules on n-type semiconductor surfaces, where $\mathrm{H}_{2}$ can be oxidized more easily than $\mathrm{CO}$. The bulk heterocontact $\mathrm{ZnO}-\mathrm{CuO}$ composite materials have been demonstrated to improve the sensitivity as well as the reproducibility of the $\mathrm{CO}$ gas sensor since the introduction of the p-type $\mathrm{CuO}$ forms a heterocontact interface with the $\mathrm{ZnO}$ [28-33]. Yanagida et al suggested that the adsorbed $\mathrm{CO}$ molecules form interface states that can change the potential barrier height and consequently the current across the junction [31]. In our case, the nanowires consisting of $\mathrm{CuO}$ and $\mathrm{ZnO}$ phases form the heterocontact interface on the nanoscale. The $\mathrm{CO}$ gas sensing properties of the composite $\mathrm{ZnO}-\mathrm{CuO}$ are expected to be improved. Therefore, a gas sensor based on the composite nanostructure film was fabricated. Because of the free-standing feature, the gas sensor is simply constructed by directly attaching two gold pads on the surface of the composite films. The $\mathrm{ZnO}-\mathrm{CuO}$ gas sensor was then exposed to $\mathrm{CO}$ gas in ambient air. As a reference, a gas sensor based on a pure $\mathrm{ZnO}$ nanowire array was also fabricated and measured. Since the sensor presented different responses at various testing temperatures and concentrations of the testing gas, we first investigated the effect of these two factors. Figures 6(a) and (b) plot the sensitivity of the $\mathrm{ZnO}-\mathrm{CuO}$ and $\mathrm{ZnO}$ gas sensors as a function of temperature and concentration of $\mathrm{CO}$ gas, 

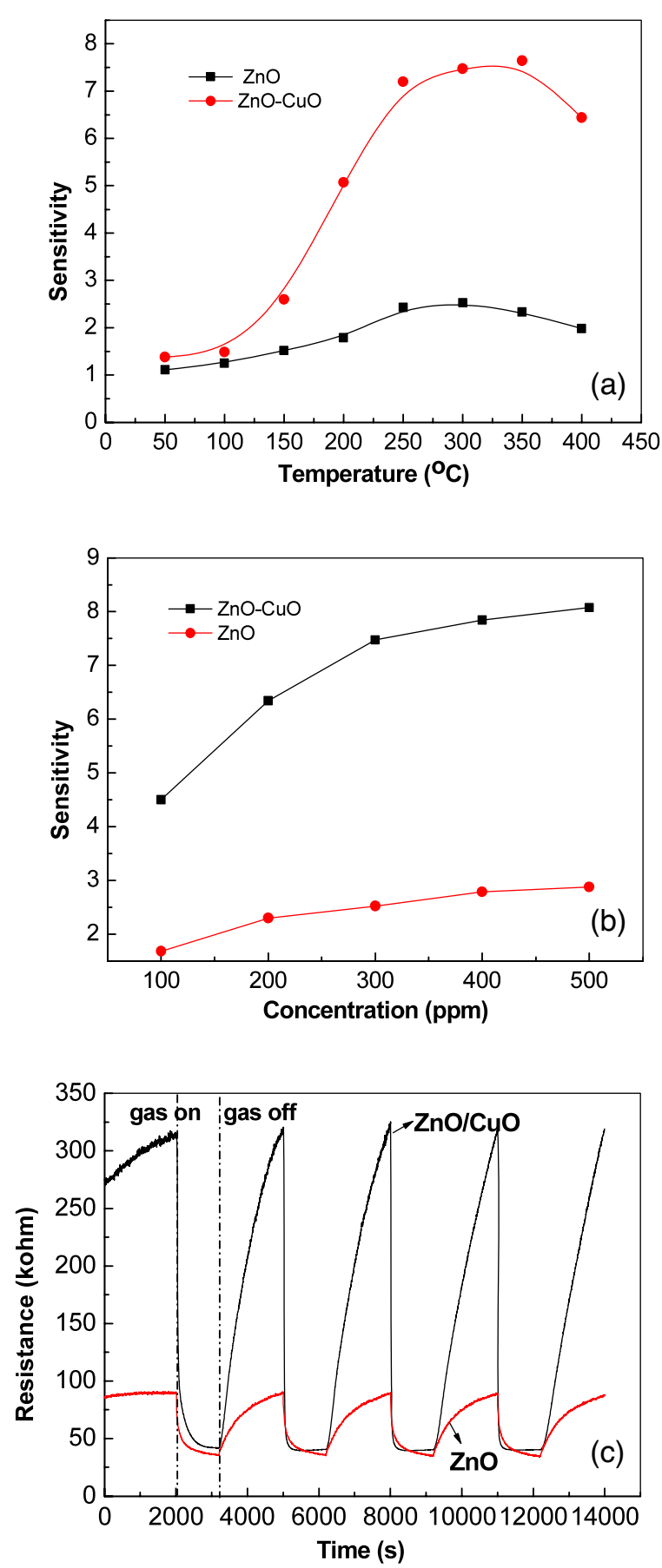

Figure 6. The sensitivity of the $\mathrm{ZnO}-\mathrm{CuO}$ composite nanostructure and $\mathrm{ZnO}$ nanorod gas sensor as a function of (a) temperature and (b) concentration of $\mathrm{CO}$ gas. (c) Sensing responses of the gas sensor based on $\mathrm{ZnO}-\mathrm{CuO}$ composite nanostructures and the $\mathrm{ZnO}$ nanowire exposed to $300 \mathrm{ppm} \mathrm{CO}$ gas at temperature $300^{\circ} \mathrm{C}$.

respectively. As can be seen from figure 6(a), the sensitivity of both $\mathrm{ZnO}-\mathrm{CuO}$ and $\mathrm{ZnO}$ sensors reaches the maximum in the temperature range from 250 to $350{ }^{\circ} \mathrm{C}$. Therefore, $300^{\circ} \mathrm{C}$ was chosen as the testing temperature to measure the sensing properties of the $\mathrm{ZnO}-\mathrm{CuO}$ sensors. In addition, the calibration curves shown in figure 6(b) indicate that the $\mathrm{ZnO}-$ $\mathrm{CuO}$ microtube sensor shows an increasing response following the increase of the gas concentration but it increases slowly for higher CO concentrations over $400 \mathrm{ppm}$. Figure 6(c) shows the sensing responses of the corresponding $\mathrm{ZnO}-\mathrm{CuO}$ composite nanostructure and the $\mathrm{ZnO}$ nanowire gas sensors when exposed to $300 \mathrm{ppm} \mathrm{CO}$ gas at $300^{\circ} \mathrm{C}$. At this temperature, the $\mathrm{ZnO}-$ $\mathrm{CuO}$ composite shows higher resistance at the initial stage than the $\mathrm{ZnO}$ nanowire, which is due to the high resistance of the $\mathrm{CuO}$ phase in the composite. In figure 6, we found that both the resistance of the composite $\mathrm{ZnO}-\mathrm{CuO}$ and $\mathrm{ZnO}$ sensors reduces in the presence of $300 \mathrm{ppm} \mathrm{CO}$. The reversible cycles of the response curve of the composite $\mathrm{ZnO}-\mathrm{CuO}$ gas sensor indicate a stable and repeatable operation, with a sensitivity $S$ of about 7.6. Although the $\mathrm{ZnO}$ nanowire gas sensor also shows a reversible response to $\mathrm{CO}$ gas at the same temperature, the sensitivity of the composite $\mathrm{ZnO}-\mathrm{CuO}$ sensor is obviously higher than that of the pure $\mathrm{ZnO}$ nanowire. The sensitivity of composite $\mathrm{ZnO}-\mathrm{CuO}$ nanostructures is over three times that of $\mathrm{ZnO}$ nanowires, indicating the improved sensitivity of the $\mathrm{ZnO}-\mathrm{CuO}$ composite to the $\mathrm{CO}$ gas. Moreover, we also found that both the response and recovery times of the composite $\mathrm{ZnO}-\mathrm{CuO}$ gas sensor are faster than those of the $\mathrm{ZnO}$ nanowire sensor. For a composite $\mathrm{ZnO}-\mathrm{CuO}$ sensor, the response and recovery times are $26 \mathrm{~s}$ and $1048 \mathrm{~s}$, respectively, while for the $\mathrm{ZnO}$ nanowire sensor, the response and recovery times are $238 \mathrm{~s}$ and $1354 \mathrm{~s}$, respectively. The response time is remarkably improved for the $\mathrm{ZnO}-\mathrm{CuO}$ sensor. These results indicate that better performance can be achieved with a composite $\mathrm{ZnO}-\mathrm{CuO}$ nanostructure film sensor compared to a single-phase nanowire $\mathrm{ZnO}$ gas sensor. We also noted that in figure 6(c) a slight resistance drift occurred, which may due to the inhomogeneous morphologies of the $\mathrm{ZnO}-$ $\mathrm{CuO}$ composite nanostructures. The free-standing composite films synthesized by the hydrothermal method consist of many spherical crowns and thus form a rough surface. We optimize the growth condition to get the uniform composite film which may help to further improve the stability of the composite $\mathrm{ZnO}-\mathrm{CuO}$ sensor. This will be our future research direction towards the better performance of the $\mathrm{ZnO}-\mathrm{CuO}$ sensor.

\section{Conclusion}

In summary, we have presented a hydrothermal method for the synthesis of free-standing composite $\mathrm{ZnO}-\mathrm{CuO}$ films on the surface of the hydrothermal solution by controlling the chemical reaction dynamics. The film is made of the assembled composite $\mathrm{CuO} / \mathrm{ZnO}$ nanostructures and possesses a flat surface on one side and a rough surface on the other side. The formation of the composite $\mathrm{CuO} / \mathrm{ZnO}$ nanostructure undergoes a two-step process in which the $\mathrm{ZnO}$ layer grew on the surface of the $\mathrm{CuO}$ nanowires. The composite $\mathrm{CuO} / \mathrm{ZnO}$ nanostructures showed remarkably improved sensing properties for $\mathrm{CO}$ gas compared to the single-phase $\mathrm{ZnO}$ nanowires. This method may also be applied in other composite systems to synthesize many other functional composite oxide nanostructures.

\section{References}

[1] Huang M H, Mao S, Feick H, Yan H Q, Wu Y Y, Kind H, Weber E, Russo R and Yang P D 2001 Science 2921897 
[2] Martinson A B F, Elam J W, Hupp J T and Pellin M J 2007 Nano Lett. 72183

[3] Jiang C Y, Sun X W, Lo G Q, Kwong D L and Wang J X 2007 Appl. Phys. Lett. 90263501

[4] Wang J X, Xie S S and Zhou W 2007 MRS Bull. 32123

[5] Zeng H, Li Z, Cai W, Cao B, Liu P and Yang S 2007 J. Phys. Chem. B 11114311

[6] Hsu Y J and Lu S Y 2004 Chem. Commun. 2102

[7] Du N, Zhang H, Chen B D, Wu J B and Yang D R 2007 Nanotechnology 18115619

[8] Wong W S, Sands T and Cheung N W 1998 Appl. Phys. Lett. 72599

[9] Zhu Y W, Zhang H Z, Sun X C, Feng S Q, Xu J, Zhao Q, Xiang B, Wang R M and Yu D P 2003 Appl. Phys. Lett. 83144

[10] Wang J X, Sun X W, Wei A, Lei Y, Cai X P, Li C M and Dong Z L 2006 Appl. Phys. Lett. 88233106

[11] Wang J X, Sun X W, Huang H, Lee Y C, Tan O K, Yu M B, Lo G Q and Kwong D L 2007 Appl. Phys. A 88611

[12] Wang J X, Sun X W, Yang Y and Wu C M L 2009 Nanotechnology 20465501

[13] Fan Z Y, Wang D W, Chang P C, Tseng W Y and Lu J G 2004 Appl. Phys. Lett. 855923

[14] Kim Y S, Hwang I S, Kim S J, Lee C Y and Lee J H 2008 Sensors Actuators B 135298

[15] Gao S Y, Yang S X, Shu J, Zhang S X, Li Z D and Jiang K 2008 J. Phys. Chem. C 11219324

[16] Zhu Y W, Yu T, Cheong F C, Xui X J, Lim C T, Tan V B C, Thong J T L and Sow C H 2005 Nanotechnology 1688
[17] Wang J X, Sun X W, Xie S S, Yang Y, Chen H Y, Lo G Q and Kwong D L 2007 J. Phys. Chem. C 1117671

[18] Bundesmann C, Ashkenov N, Schubert M, Spemann D, Butz T, Kaidashev E M, Lorenz M and Grundmann M 2003 Appl. Phys. Lett. 831974

[19] Manjón F J, Marí B, Serrano J and Romero A H 2005 J. Appl. Phys. 97053516

[20] Yu T, Zhao X, Shen Z X, Wu Y H and Su W H 2004 J. Cryst. Growth 268590

[21] Hu J Q and Bando Y 2003 Appl. Phys. Lett. 821401

[22] Zhu Y W, Sow C H, Yu T, Zhao Q, Li P H, Shen Z X, Yu D P and Thong J T L 2006 Adv. Funct. Mater. 162415

[23] Lin B X, Fu Z X and Jia Y B 2001 Appl. Phys. Lett. 79943

[24] Jin B J, Im S and Lee S Y 2000 Thin Solid Films 366107

[25] Park W I, Jun Y H, Jung S W and Yi G C 2003 Appl. Phys. Lett. 82964

[26] Zhou S M, Zhang X H, Meng X M, Zou K, Fan X, Wu S K and Lee S T 2004 Nanotechnology 151152

[27] Garces N Y, Wang L, Bai L, Giles N C, Halliburton L E and Cantwell G 2002 Appl. Phys. Lett. 81622

[28] Bae H Y and Choi G M 1999 Sensors Actuators B 5547

[29] Choi J D and Choi G M 2000 Sensors Actuators B 69120

[30] Jun S T and Choi G M 1994 Sensors Actuators B 17175

[31] Nakamura Y, Ando A, Tsurutani T, Okada O, Miyayama M, Koumoto K and Yanagida H 1986 Chem. Lett. 3413

[32] Nakamura Y, Yoshioka H, Miyayama M, Yanagida H, Tsurutani T and Nakamura Y 1990 J. Electrochem. Soc. 137940

[33] Nakamura Y, Zhuang H X, Kishimoto A, Okada O and Yanagida H 1998 J. Electrochem. Soc. 145632 